\title{
El Tribunal para la Paz y las Salas de Justicia de la JEP como órganos jurisdiccionales suigeneris*
}

The Court and Justice Chambers of the Special Jurisdiction for Peace as sui generis jurisdictional institutions

Diego Fernando Tarapués Sandino a

Universidad Santiago de Cali, Colombia

dtarapues@usc.edu.co

ORCID: https://orcid.org/0000-0003-0048-655X
DOI: https://doi.org/10.11144/Javeriana.vj69.tpsj

Recepción: 07 Octubre 2019

Aceptación: 21 Octubre 2019

Publicación: 30 Junio 2020

\section{Resumen:}

El presente artículo de reflexión plantea que tanto el Tribunal para la Paz como las Salas de Justicia de la JEP son instituciones sui generis que se han forjado gracias a la evolución de los instrumentos y órganos judiciales que se han gestado desde el derecho internacional para la determinación de responsabilidades penales en escenarios de graves violaciones de derechos humanos y a las experiencias domésticas que en materia de justicia transicional ha experimentado Colombia. Para el desarrollo de la labor encomendada a la JEP, se han creado los principios de preferencia y prevalencia que rigen como presupuestos jurisdiccionales con la finalidad de que el Tribunal para la Paz y las Salas de Justicia de la JEP concentren y absorban el conocimiento de los casos asociados con el conflicto armado, que anteriormente correspondían a diversas autoridades jurisdiccionales e incluso disciplinares y fiscales. Este artículo busca reflexionar sobre la naturaleza institucional de la JEP como juez natural del conflicto armado colombiano, destacando varios rasgos particulares de sus órganos jurisdiccionales que le diferencian de los demás jueces y tribunales nacionales. Palabras clave: Jurisdicción Especial para la Paz, Tribunal para la Paz, Salas de Justicia, principios de preferencia y prevalencia, conflicto armado.

\section{Abstract:}

This reflection article states that both the Court for Peace and the Justice Chambers of the Special Jurisdiction for Peace can be considered as sui generis jurisdictional institutions. They have been built thanks to the evolution of the judicial instruments and institutions from international law for the ascription of criminal responsibilities in scenarios of serious human rights violations and thanks to the domestic experiences that Colombia has experienced in the area of transitional justice. The principles of preference and prevalence that govern as jurisdictional budgets have been created so that the Special Jurisdiction for Peace concentrates the competence of the cases associated with the armed conflict, which previously corresponded to various jurisdictional and even disciplinary and fiscal institutions. This article aims to debate on the institutional nature of the Special Jurisdiction for Peace as a natural judge of the Colombian armed conflict, highlighting several features of its jurisdictional institutions that differentiate it from other national judges and courts.

Keywords: Special Jurisdiction for Peace, Court for Peace, Justice Chambers, principles of preference and prevalence, armed conflict.

\section{Introducción}

La JEP constituye el componente de justicia dentro del SIVJRNR ${ }^{[1]}$. Su labor principal se centra en satisfacer el derecho de las víctimas a la justicia y en cumplir con el deber estatal de investigar y juzgar las graves violaciones a los derechos humanos y las graves infracciones al Derecho Internacional Humanitario ocurridas en el desarrollo del conflicto armado colombiano ${ }^{[2]}$. Aunque claramente hace parte del ordenamiento jurídico y del sistema político colombianos, es posible afirmar que la naturaleza y los objetivos de esta institución van más allá de los mandatos nacionales de hacer justicia -en contextos ordinarios- y se

Notas de autor

a Autor de correspondencia. Correo electrónico:dtarapues@usc.edu.co 
articulan a la lucha internacional contra la impunidad en escenarios de macrocriminalidad, diferenciándose tangencialmente de los demás órganos jurisdiccionales colombianos por varios rasgos identitarios propios.

La creación de un tribunal y de unas salas de justicia posteriores a la ocurrencia de las conductas que se le asignan para su conocimiento, con mandato temporal y producto de un acuerdo político es algo atípico en la historia institucional colombiana. Lo más parecido a nivel nacional había sido la creación de Salas de Justicia y $\mathrm{Paz}^{[3]}$, sin embargo, hay que resaltar que estas se incorporaron a los Tribunal Superiores de algunos Distritos Judiciales dentro del poder judicial tradicional y que los fiscales de Justicia y Paz hacían parte de una Unidad Especial dentro de la misma Fiscalía General de la Nación ${ }^{[4]}$. Es decir, son experiencias orgánicamente diferenciables y con alcances jurisdiccionales divergentes, ya que en el modelo estructurado en Justicia y Paz no se creó una jurisdicción especial con órganos propios y con autonomía administrativa y financiera, ni tampoco se diseñó a partir de lo acordado en una negociación entre los actores.

Si bien la JEP parte de la experiencia adquirida con el modelo implementado a través de la Ley de Justicia y Paz (Ley 975 de 2005) ${ }^{[5]}$ y de los presupuestos constitucionales incorporados a través del denominado Marco Jurídico para la Paz (AL 01 de 2012) ${ }^{[6]}$, la creación orgánica e institucional de la JEP -por lo menos de su órgano judicial de cierre, es decir, el Tribunal para la Paz- encuentra sus raíces en experiencias foráneas. Para la JEP se han creado tribunales ex post facto y ad hoc para investigar y juzgar de manera especializada ciertos delitos que, además, han sido cometidos con anterioridad a la creación del respectivo órgano jurisdiccional $^{[7]}$.

En este orden de ideas, a continuación, se hará una aproximación general a los principales rasgos que concurren en el Tribunal para la Paz y en las Salas de Justicia de la JEP, con el propósito de comprender las particularidades existentes en su diseño institucional, las cuales le diferencian de los demás órganos jurisdiccionales que tradicionalmente han conocido y judicializado los crímenes perpetrados en el marco del conflicto armado colombiano.

\section{La naturaleza institucional de la JEP}

El modelo inicial acordado en La Habana contemplaba un diseño institucional de la JEP, tanto del Tribunal para la Paz como de las Salas de Justicia, más orientado a las tendencias contemporáneas en el derecho internacional y extranjero de establecer tribunales penales híbridos con una composición mixta de magistrados ${ }^{[8]}$. Este tipo de órganos jurisdiccionales (bybrid courts) hacen parte de una nueva generación de cortes (penales) con connotación internacional [9], a los cuales se les ha llegado a llamar tribunales penales "internacionalizados" ${ }^{[10]}$. Estos se caracterizan no solo por su composición mixta donde convergen jueces nacionales y extranjeros, sino que además encuentra fundamentos jurídicos para su constitución y funcionamiento tanto en el derecho nacional como en el derecho internacional ${ }^{[11]}$. Son tribunales que no surgen de la imposición de organismos internacionales, sino que se crean y se legitiman jurídicamente desde adentro, es decir, desde el propio Estado soberano, pero además cuentan con el apoyo férreo de la comunidad internacional, bien sea de un conjunto de países o de alguna organización internacional ${ }^{[12]}$.

Si bien en el caso de la JEP su conformación no se concretó como se había acordado inicialmente, a partir de una convergencia de magistrados nacionales y una minoría de magistrados extranjeros que le hubiese aportado a su naturaleza de corte internacionalizada, se conservó una atípica conformación a través de la participación de juristas extranjeros como amicis y con un proceso de selección de sus integrantes por parte de un comité conformado mayoritariamente por extranjeros. Además, no se debe pasar por alto, entre otras cosas, que normas internacionales hacen parte del derecho que debe aplicar la JEP para la califi cación jurídica de las conductas ${ }^{[13]}$, que de acuerdo con el texto constitucional se debe garantizar la "libertad de escoger abogado acreditado para ejercer en cualquier país" "14] y que el apoyo de la comunidad internacional para su creación, implementación e incluso financiación y funcionamiento administrativo ha sido significativo $^{[15]}$. 
En este sentido, se pueden evidenciar algunas particularidades que deben considerarse a la hora de analizar la naturaleza institucional de los órganos jurisdiccionales que conforman la JEP y que explican los rasgos identitarios propios que se advierten de entrada ${ }^{[16]}$. Algunos de estos rasgos se encuentran en su origen político, en el fundamento de su jurisdicción a través de los principios de preferencia y prevalencia, en su conformación, proceso de selección de jueces, ubicación institucional, en la forma mediante la cual adelanta su labor jurisdiccional, así como en el derecho internacional aplicable para el ejercicio de sus funciones. Estos rasgos institucionales pasarán a revisarse a continuación.

\section{Origen político y negociado}

En primer lugar, hay que tener presente que la JEP existe en virtud de un acuerdo político suscrito entre la extinta guerrilla de las FARC-EP y el Gobierno Nacional, acuerdo dirigido a terminar el conflicto armado que sostuvieron las fuerzas regulares del Estado colombiano con lo que fue dicha agrupación insurgente ${ }^{[17]}$. Este es un aspecto de suma importancia que no se debe pasar por alto, por el contrario, debe ser el punto de partida para su comprensión holística. Pues bien, la creación de la JEP como componente judicial del actual modelo de justicia transicional se da luego de la transición (política) hacia la paz que fue acordada con esta organización y, por consiguiente, su creación institucional puede entenderse como una clara manifestación de la lexpacificatoria ${ }^{[18]}$.

Este proceso de transición política se puede clasificar en términos comparativos como un proceso de transición de tipo "responsabilizante" en lo referente a su contenido ${ }^{[19]}$ y propio del tipo de "transiciones democráticamente legitimadas" respecto al procedimiento que se siguió ${ }^{[20]}$. Es decir, no se trató de modelos impuestos de judicialización punitiva, como tampoco de modelos amnésicos o compensatorios, bien sea concertados o autodecretados, en los que se suelen invisibilizar a las víctimas ${ }^{[21]}$. Por el contrario, bajo lo establecido en la "Declaración de principios" de junio 7 de $2014^{[22]}$, las partes en negociación vislumbraron todas las alternativas posibles para resolver la situación jurídico penal de las partes inmersas en el conflicto, atendiendo ante todo a la satisfacción de los derechos de las víctimas y a lo establecido en el DIDH, DIH y DPI.

Este modelo se centró en la creación de un sistema integral y holístico enfocado en los derechos de las víctimas, donde, entre otras cosas, la persecución penal de los crímenes (internacionales) más representativos que fueron cometidos por los máximos responsables es irrenunciable y los comparecientes deben cumplir a cabalidad un régimen de condicionalidad dirigido a garantizar que se contribuya con los mecanismos judiciales y extrajudiciales que integran el SIVJRNR. Esto, con el propósito de garantizar el cumplimiento de las obligaciones adquiridas y la satisfacción de los derechos de las víctimas a la verdad, justicia, reparación y no repetición ${ }^{[23]}$.

En efecto, la creación de la JEP es un pacto político resultado de la negociación del "Acuerdo parcial sobre las Víctimas del Conflicto" de diciembre 15 de $2015^{\text {[24] }}$. Este fue el punto de la agenda más difícil ${ }^{[25]}$, en donde más se prolongó la negociación e incluso se tuvo que conformar una comisión especial compuesta por tres delegados de cada una de las partes en negociación, con el propósito de construir de manera técnica y consensuada lo que había sido imposible estructurar en la mesa de negociación en La Habana ${ }^{[26]}$.

Producto de este acuerdo, las FARC-EP se comprometieron a comparecer ante la justicia. Para cumplir con la dejación de armas, así como con el compromiso de rendición de cuentas ante la justicia institucional del Estado \#institucionalidad que habían desconocido y combatido por décadas\#, las FARC-EP reclamaron políticamente la creación de un juez natural preferente. Asimismo, exigieron condiciones que brindaran seguridad jurídica frente a lo pactado en el Acuerdo Final. Por esta razón, no solo se creó la JEP para avocar conocimiento de manera preferente y prevalente sobre las conductas cometidas en el conflicto armado, sino 
que también se constitucionalizó la garantía de no extradición como mecanismo judicial para defender la seguridad jurídica y el principio del juez natural ante eventuales requerimientos de autoridades judiciales extranjeras $^{[27]}$.

Con relación a los miembros de la fuerza pública que estén implicados en conductas cometidas en el marco del conflicto armado, se decidió que también podrían y deberían resolver su situación jurídica en este nuevo escenario judicial. Respecto a los agentes del Estado que no hayan sido miembros de la fuerza pública, al igual que frente al caso de terceros cuyas conductas también estén relacionadas con el conflicto armado, se fijó que podrían someterse a la JEP, pero de manera voluntaria ${ }^{[28]}$. Por esta razón, la Corte Constitucional ha fijado que la JEP representa "el juez natural de los excombatientes" [29] , debido a esa obligatoriedad de comparecencia para las partes involucradas en la confrontación bélica.

Sin embargo, desde la perspectiva del derecho penal de acto, es posible calificar a la JEP no tanto como juez natural de los excombatientes, sino mejor como el juez natural de las conductas perpetradas en el marco del conflicto armado colombiano. Pues bien, incluso en los casos de comparecencia voluntaria de terceros y de aquellos servidores públicos que no fueron combatientes, solamente es posible si se trata de conductas relacionadas directa o indirectamente con el conflicto armado ${ }^{[30]}$.

\section{Conocimiento preferente y prevalente de las conductas cometidas en el conflicto}

Para fundamentar el ejercicio de la labor judicial encomendada a la JEP se creó el principio de preferencia que rige como presupuesto jurisdiccional para absorber y concentrar el conocimiento de los casos asociados con el conflicto armado interno, los cuales anteriormente correspondían de manera difusa a diversas autoridades no solo jurisdiccionales, sino también disciplinares y fiscales.

Este principio se incorporó en la Constitución Política por medio del art. transitorio 5 del art. 1 del AL 01 de 2017. De conformidad con este principio, exclusivo de la justicia transicional colombiana, la JEP, como componente de justicia del SIVJRNR y según lo pactado en el Acuerdo Final, administra justicia de manera transitoria y autónoma, conociendo "de manera preferente sobre todas las demás jurisdicciones y de forma exclusiva de las conductas cometidas con anterioridad al $1 .^{\circ}$ de diciembre de 2016, por causa, con ocasión o en relación directa o indirecta con el conflicto armado, por quienes participaron en el mismo, en especial respecto a conductas consideradas graves infracciones al Derecho Internacional Humanitario o graves violaciones de los Derechos Humanos" [31].

El principio de preferencia resulta esencial para activar la competencia de la JEP, del mismo modo que lo es \#aunque sin ser lo mismo\# el principio de complementariedad para la CPI, el principio de subsidiaridad para la Corte IDH o el principio de jurisdicción universal para un tercer Estado que se propone investigar y judicializar crímenes internacionales que ocurrieron en otro Estado. Pues bien, en ninguno de estos escenarios judiciales \#incluyendo la JEP\# es posible conocer directamente de un caso que compete a las autoridades judiciales ordinarias sin antes darse los presupuestos procesales preliminares que exigen cada uno de estos principios, para activar el ejercicio de su jurisdicción.

En ese sentido, este principio constitucional es el eje que sustenta y dinamiza los alcances jurisdiccionales de la JEP, al tratarse de una jurisdicción especializada que funciona en el ámbito institucional nacional, en donde les sustrae funciones a los órganos tradicionales del poder judicial y a órganos de control disciplinar y fiscal. Sin este principio no habría claridad ni precisión de lo que le corresponde investigar, juzgar y resolver a la JEP, ya que a partir de él se posibilita el conocimiento ad hoc y expost de los órganos de esta jurisdicción.

El establecimiento de un principio tan imperioso para fundamentar el conocimiento de los casos sobre los cuales la JEP puede decidir, conlleva a una estricta delimitación de los factores competenciales concurrentes que activan el carácter preferente de esta jurisdicción. Por esa razón, la disposición que crea este principio trae 
consigo, de forma inherente, la demarcación de aquellos criterios que delimitan el alcance del ejercicio del principio Kompetenz-Kompetenz de los órganos jurisdiccionales de la JEP.

Tal como se desprende literalmente del art. transitorio 5 del art. 1 del AL 01 de 2017, el conocimiento preferente y exclusivo que tiene la JEP sobre las otras jurisdicciones solo se da si concurren tres presupuestos: (i) con relación a la ratione personae deben ser conductas perpetradas por los actores que participaron en el conflicto armado, atendiendo al universo delimitado de combatientes y civiles sometidos y aceptados en el SIVJRNR ${ }^{[32]}$; (ii) respecto a la ratione temporis las conductas deben haber sido cometidas durante la existencia del conflicto armado, considerando como referente temporal la entrada en vigor del Acuerdo Final -hasta antes del 1 de diciembre de 2016-, siendo la única excepción los delitos relacionados con el proceso de dejación de armas ${ }^{[33]}$; y (iii) en lo atinente a la ratione materiae deben ser conductas causadas, ocasionadas o relacionadas de manera directa o indirecta con el conflicto armado, atendiendo especialmente a conductas consideradas como graves violaciones o infracciones al DIDH y al DIH ${ }^{[34]}$.

Como se puede ver, el conflicto armado constituye un elemento transversal que está presente en los factores temporal, material y personal que prevé el principio de preferencia al momento de determinar la competencia de la JEP. Su ubicuidad se explica por la finalidad esencial del SIVJRNR de edificar componentes que permitan esclarecer y superar lo acontecido, justamente, en el conflicto armado colombiano, lo que vuelve a la JEP el componente de justicia que debe resolver la situación jurídico penal de las conductas asociadas con el conflicto. La valoración de la relación con el conflicto armado se puede dar procesalmente en diferentes momentos, no solo al activar competencia, sino también al conceder beneficios de menor y mayor entidad. Por esta razón, el órgano de cierre hermenéutico de la JEP ha definido que especialmente la relación material con el conflicto armado se debe evaluar en diferentes niveles de intensidad, según el estado del proceso y las pruebas $^{[35]}$.

A partir de aquella finalidad orientada a la superación, esclarecimiento y determinación de responsabilidades derivadas de los hechos producidos en el marco del conflicto armado es que la JEP debe apelar al conocimiento exclusivo y preferente que la Constitución le ha brindado. Este conocimiento preferente sobre los delitos cometidos en el marco del conflicto va de la mano con la competencia prevalente que ejerce la JEP sobre los asuntos que admite.

En efecto, junto con el principio de preferencia que demarca la labor de la JEP, el texto constitucional ha previsto su carácter prevalente para establecer que los órganos jurisdiccionales de esta nueva jurisdicción tienen una competencia que se sobrepone por encima de la que pueda llegar a tener cualquier otra institución. En estricto sentido, el art. transitorio 6 del art. 1 del AL 01 de 2017 establece que la JEP "prevalecerá sobre las actuaciones penales, disciplinarias o administrativas por conductas cometidas con ocasión, por causa o en relación directa o indirecta con el conflicto armado, al absorber la competencia exclusiva sobre dichas conductas" ${ }^{[36]}$. Estos alcances de la prevalencia se reproducen en el art. 36 de la Ley Estatutaria de la JEP, aunque incorporando además las actuaciones fiscales ${ }^{[37]}$.

De esta disposición constitucional y legal que fija la prevalencia, la Corte Constitucional además extrae la fuente constitucional para la determinación del fuero de atracción de la JEP. Al respecto, la Corte señala: "El tema que se incorpora en la citada disposición es el de la competencia y prevalencia de la JEP sobre actuaciones, tanto penales como disciplinarias, fiscales y administrativas, adelantadas en relación con conductas vinculadas con el conflicto armado, también denominado fuero de atracción" ${ }^{[38]}$.

El art. transitorio 6 del art. 1 del AL 01 de 2017 igualmente fija en su segundo inciso el alcance de esta competencia prevalente en la revisión o extinción de responsabilidades que van más allá de la determinación o extinción de responsabilidad penal, al indicar que con relación a las

sanciones o investigaciones disciplinarias o administrativas, incluidas las pecuniarias impuestas a personas naturales en cualquier jurisdicción, la competencia de la Jurisdicción Especial para la Paz se limitará bien a anular o extinguir la responsabilidad o la sanción disciplinaria o administrativa impuesta por conductas cometidas con ocasión, por causa o en 
relación directa o indirecta con el conflicto armado, o bien a revisar dichas sanciones, todo ello a solicitud del sancionado o investigado ${ }^{[39]}$.

Finalmente, el art. transitorio 27 del art. 1 del AL 01 de 2017 plantea una cláusula de ultraactividad relacionada con la aplicación prevalente del Acuerdo Final en caso de que se expidan normas posteriores que "provocaren que los (combatientes o no combatientes que hayan cometido conductas relacionadas directa o indirectamente con el conflicto) sean excluidos de la competencia de la Jurisdicción Especial para la Paz, o tuvieren como resultado la inaplicación de dicha jurisdicción"; frente a estas personas "el Tribunal Especial para la Paz ejercerá su jurisdicción preferente en las materias de su competencia conforme al presente Acto Legislativo", sin importar lo que establezcan normas contrarias a futuro. Al respecto, la Corte Constitucional ha sostenido que el Acuerdo Final resalta "el carácter autónomo, preferente y excluyente de la JEP sobre los asuntos de su competencia, descartando a la justicia ordinaria y a cualquier otra que se instale en el futuro" ${ }^{[40]}$.

En suma, no solo el carácter preferente y exclusivo de la JEP devela un nuevo escenario de concentración judicial para el conocimiento de toda conducta que se relacione con el conflicto armado bajo los presupuestos (personal, temporal y material) establecidos en el Acuerdo Final, sino que además el carácter prevalente, tanto funcional como temporal, evidencian una estructuración institucional atípica si se le compara con los demás órganos jurisdiccionales colombianos.

\section{Juristas extranjeros en su conformación}

Tal como se indicó al inicio, el diseño inicial de la JEP se caracterizaba por una composición mixta similar a los tribunales híbridos que se han creado recientemente en países como Timor Oriental, Camboya, Kosovo, Sierra Leona y Líbano ${ }^{[41]}$. En ese sentido, el primer documento del Acuerdo Final contemplaba la siguiente disposición al momento de fijar la composición del Tribunal para la Paz: "Deberán elegirse 20 magistrados colombianos, y además 4 extranjeros que actuarán en las Secciones en caso de ser solicitados. (...) En el supuesto de incrementarse el número de magistrados, se aumentará proporcionalmente el número de magistrados extranjeros" ${ }^{[42]}$. De forma similar se contemplaba la participación de jueces extranjeros en las tres Salas de Justicia, pues se había acordado lo siguiente: "Respecto a la nacionalidad de los magistrados podrá haber hasta dos magistrados extranjeros por Sala, a solicitud del compareciente" ${ }^{[43]}$.

Por otra parte, en el "Acuerdo de desarrollo del numeral 23 del 'Acuerdo de creación de una jurisdicción especial para la paz' del 15 de diciembre de 2015”, propiamente en el punto 5.3, referente al acuerdo complementario sobre el SIVJRNR, se reafirmaba esta composición mixta de la magistratura tanto en el Tribunal como en las Salas de Justicia: "En el Tribunal para la Paz ejercerán la magistratura un mínimo de 20 magistrados o magistradas colombianos y 4 magistradas o magistrados extranjeros. En las Salas de Justicia de la Jurisdicción Especial para la Paz ejercerán la magistratura 18 magistradas o magistrados colombianos y 6 magistradas o magistrados extranjeros". Además, en este mismo documento dentro del diseño del componente investigativo y acusatorio de la JEP se fijaba también la participación de fiscales extranjeros de la siguiente forma: "La Unidad de Investigación y Acusación de la Jurisdicción Especial para la Paz estará integrada por un mínimo de dieciséis (16) fiscales, de los cuales doce (12) serán de nacionalidad colombiana y cuatro (4) serán de nacionalidad extranjera”.

La inclusión de jueces y fiscales extranjeros dentro de la JEP fue requerida principalmente por las FARCEP como una garantía adicional de independencia, a lo cual el Gobierno no se opuso. En consecuencia, ambas partes estimaron en el marco de la negociación que "la participación de jueces extranjeros garantizaría la compatibilidad de la jurisprudencia con los estándares internacionales" [44]

Si bien la concreción de la participación institucional de extranjeros en calidad de magistrados tanto del Tribunal como de las Salas hubiese sido un elemento que le hubiera acercado más a la naturaleza institucional propia de tribunales mixtos, el desmonte de estos jueces y fiscales extranjeros y la readaptación institucional 
de la JEP a partir del segundo y definitivo Acuerdo de Paz, no desdibujó del todo las particularidades jurídicas e institucionales de estos nuevos órganos jurisdiccionales asociadas con el derecho internacional. Así se evidencia, por ejemplo, con la conservación de la participación de juristas extranjeros dentro de las labores de esta nueva jurisdicción, si bien ya no como magistrados, sí al menos bajo la figura de amicus curiae ${ }^{[45]}$.

Tal como lo resaltan Ambos y Aboueldahab, la figura del amicus curiae es "ampliamente reconocida por los tribunales de derecho (penal) internacional", donde el amici se caracteriza por su participación independiente dentro de los procesos, proporcionando "información especializada sobre cuestiones pertinentes en casos en los que se requiera de sus conocimientos especializados", con el propósito de "facilitar la apropiación por parte de los magistrados de los tribunales de elementos de juicio, información y valoraciones que puedan ser necesarias para la toma de alguna decisión en sus procesos" ${ }^{[46]}$.

Las particularidades con que quedó consignada esta figura no solo en el Acuerdo Final, sino también en la reforma constitucional que le dio vida a la JEP, hacía pensar que mediante esta nueva figura se cumplía incluso "un papel cuasi-judicial" [47]. Pues bien, además de las singularidades relacionadas con la restricción numérica de amicis, así como de los requisitos y proceso de selección de estos por parte del mismo Comité de Escogencia que seleccionó a los magistrados, existía una expresión normativa en los incisos $2 .^{\circ}$ y $3 .^{\circ}$ del artículo transitorio 7 del artículo 1 del AL 01 de 2017 que señalaba: "[c]uando se requiera la intervención de los juristas extranjeros, estos participarán en los debates de la Sección o [Sala] en la que se hubiera requerido su intervención, en las mismas condiciones que los magistrados, pero sin derecho de voto".

Esta disposición constitucional facultaba a los juristas extranjeros para hacer parte de los procesos deliberativos y decisorios (presenciales) de las Secciones y Salas en las mismas condiciones de los magistrados titulares, con la única salvedad de que no contaban con derecho a voto, el cual se reservaba a los magistrados (colombianos). Sin embargo, esta facultad de los amicis fue declarada inexequible por la Corte Constitucional, la cual estimó que por esta vía se "invade y obstruye la realización de la labor judicial" [48] , y con ello condujo a que los amicis estén formalmente en la normativa constitucional, legal e interna de la JEP ${ }^{[49]}$, pero que en la práctica no cumplan el papel que se preveía en el Acuerdo Final.

\section{Proceso de selección por comité de escogencia internacionalizado}

Además de la figura extraordinaria del amicus curiae, la conformación de los órganos jurisdiccionales de la JEP se diferencia significativamente de los demás tribunales ordinarios de justicia que existen en Colombia, por la especialísima forma en que fueron seleccionados no solo sus jueces y amicis que hacen parte de la magistratura, sino también el director de la Unidad de Investigación y Acusación y el Secretario Ejecutivo de esta jurisdicción.

En efecto, el proceso de creación no solo de la JEP, sino de todo el SIVJRN implicó a la vez el diseñó de un Comité de Escogencia (mixto) mediante el Decreto (con fuerza de ley) 587 de 2017, el cual siguió las orientaciones dadas por el parágrafo $1^{\circ}$ del art. transitorio 7 del artículo 1 del AL 01 de 2017 para la escogencia de los altos funcionarios de la JEP, de la Comisión para el Esclarecimiento de la Verdad y de la Unidad de Búsqueda de Personas Desaparecidas.

Este Comité de Escogencia que cumplió un papel transitorio, autónomo e independiente estuvo conformado por tres miembros extranjeros y dos nacionales, lo cual develó una significativa representación de actores de la comunidad internacional en el proceso objetivo de conformación de la JEP. Lo anterior de conformidad con el art. 2 del decreto que establecía que los miembros de este Comité serían los delegados designados por: (i) la Sala Penal de la Corte Suprema de Justicia, (ii) el Secretario General de Naciones Unidas, (iii) la Comisión Permanente del Sistema Universitario del Estado, (iv) el presidente de la Corte Europea de Derechos Humanos, y (v) la delegación en Colombia del Centro Internacional de Justicia Transicional $(\mathrm{ICTJ})^{[50]}$. 
Apartándose del tradicional modelo de escogencia por cooptación con el que se eligen los magistrados de la Corte Suprema de Justicia y del Consejo de Estado, así como también del especialísimo procedimiento de selección de magistrados de la Corte Constitucional por parte del Senado luego de evaluar las ternas que envían el Presidente de la República, la Corte Suprema de Justicia y el Consejo de Estado, el Comité de Escogencia adelantó su labor bajo un proceso transparente realizado a partir de una convocatoria pública y mediante el empleo de medios tecnológicos incluyentes de consulta y participación. Además, este proceso de selección estuvo condicionado normativamente a que cada escogencia se debía dar por una "mayoría de 4/5 de los miembros participantes en la votación, con un sistema de votación que prom[ovió] el consenso" [51].

\section{Estructura integral y autónoma}

Más allá de la creación de un tribunal o de unas salas especializadas, lo acordado en La Habana cimentó toda una jurisdicción autónoma, ad hoc y ex post facto, para resolver la situación jurídico penal de los excombatientes; e investigar, juzgar y determinar la responsabilidad penal individual de las más graves violaciones a los derechos humanos ocurridas en casi medio siglo de guerra irregular. De conformidad con el AL 01 de 2017, la JEP cuenta con un régimen legal propio y con autonomía administrativa, presupuestal y técnica y todos sus órganos en conjunto administran justicia de manera transitoria y autónoma, orientados por los objetivos constitucionales de: (i) satisfacer el derecho de las víctimas a la justicia; (ii) ofrecer verdad a la sociedad colombiana; (iii) proteger los derechos de las víctimas; (iv) contribuir al logro de una paz estable y duradera; $y(v)$ adoptar decisiones que otorguen plena seguridad jurídica a quienes participaron de manera directa o indirecta en el conflicto armado interno ${ }^{[52]}$.

Desde el ámbito judicial, a la JEP se le han conferido tres misiones funcionales: la acusatoria, la jurisdiccional y la de vigilancia ${ }^{[53]}$. De conformidad con lo señalado por la Corte Constitucional, cada una de estas funciones tiene una delimitación temporal; en este sentido, advierte la Corte que

[e]l artículo transitorio 15 determina que el plazo para la función acusatoria es de 10 años contados a partir de la entrada efectiva en funcionamiento de la totalidad de las salas y secciones de la JEP, y que el de la función jurisdiccional es de cinco años adicionales, plazo este que en todo caso puede ser prorrogado mediante ley, a solicitud de los magistrados, y que la Sección de Estabilidad y Eficacia puede constituirse en cualquier momento. [54]

Los mismos plazos están contemplados en la Ley Estatutaria de Administración de Justicia de la JEP, la cual además precisa que "la conclusión de las funciones y objetivos misionales de la JEP, en cualquiera de sus salas o secciones, no podrá ser superior a 20 años" ${ }^{[55]}$.

En este sentido, la JEP no puede entenderse como una corporación de la misma forma en que son vistas a nivel nacional altos tribunales como la Corte Constitucional, el Consejo de Estado o la Corte Suprema de Justicia o a nivel internacional la Corte Interamericana de Derechos Humanos o el Tribunal Europeo de Derechos Humanos. La JEP es algo más grande y estructurado que una corporación, representa una jurisdicción completa que agrupa a un conjunto de órganos, en donde el Tribunal para la Paz obra como alta corte, siendo la máxima instancia de esta jurisdicción y, por consiguiente, actúa como órgano judicial de cierre $^{[56]}$. Así lo ha señalado expresamente la jurisprudencia constitucional al señalar que la JEP

conforme al artículo transitorio 7 del Acto Legislativo 01 de 2017, está conformada por tres Salas, el Tribunal para la Paz, la Unidad de Investigación y Acusación y la Secretaría Ejecutiva. Adicionalmente, dispone de una instancia de gobierno. De esta manera, la JEP no es una Corporación, sino que es una jurisdicción con diferentes órganos, cuyo órgano de cierre es el Tribunal para la Paz y dispone de unas características especiales asignadas por el Acto Legislativo 01 de 2017. [57]

En este orden de ideas, los órganos jurisdiccionales de la JEP están encabezados por el Tribunal para la Paz ${ }^{[58]}$ que, además de ser el alto tribunal de la jurisdicción, es el único encargado del juzgamiento a través de 
sus cuatro Secciones. Dos de estas Secciones son de Primera Instancia y su conocimiento varía en función del reconocimiento o no de responsabilidad de los comparecientes, lo cual a su vez demarca el tipo de juzgamiento que se adelantará a través de procesos dialógicos o adversariales, respectivamente ${ }^{[59]}$. Una Sección de Revisión a la cual se le han asignado un conjunto de funciones particulares como, por ejemplo, la de dirimir conflictos de competencia dentro de la JEP o de resolver las solicitudes de garantía de no extradición, pero que, ante todo, enfoca su labor en los procedimientos judiciales de revisión de sentencias y de sustitución de sanciones propias del SIVJRNR en los casos donde ya hay condenas por conductas no amnistiables ni renunciables de persecución penal ${ }^{[60]}$. También hay una Sección de Apelación que ejerce como segunda instancia de las Salas y Secciones y que, además, ha sido encomendada legalmente como órgano de cierre hermenéutico de la JEP ${ }^{[61]}$. Finalmente, se le confiere al Tribunal para la Paz la labor de cumplimiento y observancia de las decisiones judiciales que tome la JEP a través de la aún no instalada Sección de Estabilidad y Eficacia ${ }^{[62]}$.

Junto con el Tribunal para la Paz, la magistratura de la JEP está conformada por otros tres órganos jurisdiccionales que son las Salas de Justicia de Reconocimiento de Verdad, de Responsabilidad y de Determinación de los Hechos y Conductas ${ }^{[63]}$, de Amnistía o Indulto ${ }^{[64]}$ y de Definición de Situaciones Jurídicas ${ }^{[65]}$. Estas Salas de Justicia fueron creadas para coadyuvar en la resolución de la situación jurídica de los comparecientes, aunque sin asignárseles funciones de juzgamiento ${ }^{[66]}$. Por esta razón, las Salas de Justicia no emiten sentencias ni autos conducentes a determinar responsabilidad penal, sino que su labor de definir situaciones jurídicas la adelanta mediante resoluciones judiciales.

Tal como lo establece el ordenamiento constitucional y lo ha reiterado la jurisprudencia constitucional, esta nueva jurisdicción no solo se conforma por los cuatro órganos jurisdiccionales autónomos que estructuran la magistratura, sino que además han sido creados constitucionalmente la Unidad de Investigación y Acusación ${ }^{[67]}$, que es el órgano encargado de realizar las investigaciones judiciales correspondientes y de adelantar el ejercicio de la acción penal dentro de la JEP, así como la Secretaría Ejecutiva que no es considerada como un órgano, sino como una institución constitutiva de la JEP ${ }^{[68]}$ que está encargada de la administración, gestión y ejecución de sus recursos ${ }^{[69]}$.

Pese a la pluralidad de órganos constitucionales que convergen en la JEP con funciones diferentes y autónomas, esta jurisdicción se encuentra representada externamente en una sola figura, creada igualmente por norma constitucional, que es la Presidencia de la JEP ${ }^{[70]}$. El magistrado que asume la presidencia de la JEP no representa solamente al Tribunal para la Paz como corporación judicial máxima dentro de esta jurisdicción y a toda la magistratura en su conjunto, incluyendo a las tres Salas de Justicia, sino que su representación además comprende a todo el conjunto de instituciones constitucionales de la JEP. Lo mismo sucede con el Órgano de Gobierno de la JEP, el cual toma las principales decisiones administrativas del conjunto de órganos, instituciones y dependencias de toda la jurisdicción ${ }^{[71]}$. Estas instituciones de rango constitucional que estructuran conjuntamente la JEP pueden verse en la figura 1. 


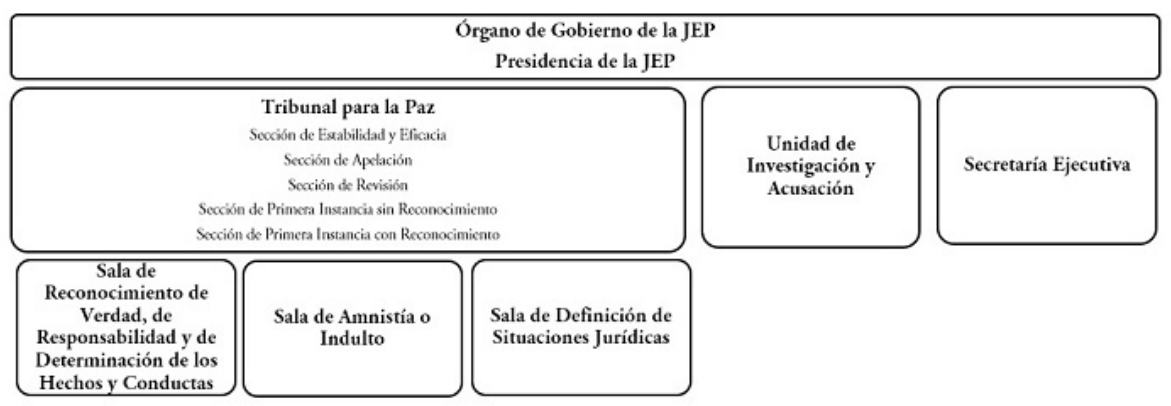

FIGURA 1.

Estructura institucional de la JEP

Fuente: elaboración propia

Aparte de estos órganos e instituciones constitucionales, la Ley Estatutaria de Administración de Justicia de la JEP establece la creación del Comité de Coordinación del SIVJRNR, el cual también se encuentra regulado en el Reglamento Interno de la JEP ${ }^{[72]}$. Además, en el marco de la autonomía administrativa, presupuestal y técnica conferida por la Constitución, la JEP ha diseñado un conjunto de dependencias y cuerpos colegiados creados reglamentariamente. Estos son: el Grupo de Análisis de la Información (GRAI) y su Comité de Dirección, la Secretaría Judicial, la Relatoría, la Comisión Territorial y Ambiental, la Comisión Étnica y la Comisión de Género ${ }^{[73]}$.

\section{Ubicación institucional por fuera del poder judicial tradicional}

Junto a esta forma particular de estructuración interna y de representación externa, vale resaltar que la JEP ha sido configurada como una jurisdicción especial y autónoma por fuera del poder judicial tradicional. A diferencia del modelo diseñado mediante la Ley de Justicia y Paz, la JEP se encuentra al margen de la tradicional rama judicial del poder público, componente de la arquitectura constitucional que agrupa a las diferentes jurisdicciones, es decir, a la ordinaria, la contencioso administrativa, la constitucional e incluso la especial de las comunidades indígenas, siendo la única excepción la jurisdicción penal militar que se encuentra adscrita al poder ejecutivo ${ }^{[74]}$.

En efecto, la JEP se inserta en el sistema político del Estado colombiano dentro de una estructura institucional independiente y temporal, en la que se edifica el SIVJRNR en su conjunto, sistema que es ajeno a cualquier poder público tradicional existente y que ha sido incorporado a través de un título transitorio de la Constitución. La especificidad de la ubicación institucional de esta jurisdicción, la fuerte autonomía e independencia que le ha dado el ordenamiento constitucional y los objetivos que le ha fijado la Constitución resaltan aún más los aspectos diferenciadores de los órganos jurisdiccionales de la JEP en relación con los otros tribunales nacionales.

Por las razones anteriores, la Corte Constitucional ha precisado que el AL 01 de 2017

no solo alteró ex post el esquema regular de distribución de competencias jurisdiccionales, sino que, además, al hacerlo, traslado sus competencias a un organismo creado ex post y ad hoc, separado del poder judicial, y estructurado a partir de objetivos y principios diferentes de los que dieron lugar a la Rama Judicial en la Constitución. ${ }^{[75]}$

Justamente por esos rasgos propios dados por su carácter ad hoc y ex post facto, sumado a que fue producto de la negociación política entre el Gobierno y las extintas FARC-EP, es que la Corte concluye que la JEP no puede ser juez natural de terceros civiles, ni de agentes del Estado que no hayan sido miembros de la fuerza pública $^{[76]}$. 


\section{Forma atípica en que adelanta su labor jurisdiccional}

Además de estas características institucionales de la JEP que le diferencian del resto de instituciones que hacen parte del poder judicial colombiano, se debe agregar un aspecto relevante en relación con su quehacer jurisdiccional. Respecto al conocimiento de los casos de su competencia, el trámite de los procesos no inicia, ni se adelanta bajo la tradición procesal del ejercicio de la acción penal que ejerce de oficio la Fiscalía o que adelanta ésta luego del conocimiento de la noticia criminal mediante denuncia, querella o petición especial, tal como sucede en la justicia penal ordinaria ${ }^{[77]}$.

Efectivamente, la JEP “no recibe ni tramita denuncias individuales”, así lo ha indicado la Corte Constitucional, aunque refiriéndose a un caso concreto de una persona que presentó una acción de tutela contra la JEP en la que planteaba poner en conocimiento su situación como presunta víctima. Entre otras cosas, advierte la Corte:

En rigor, la Jurisdicción Especial para la Paz no recibe ni tramita denuncias individuales de presuntas víctimas. Estas deben promoverse y adelantarse ante la Fiscalía General de la Nación (...). En ese orden, quien desee acceder a la JEP, en calidad de víctima, debe hacerlo inicialmente mediante los informes colectivos correspondientes, presentados a la Sala de Reconocimiento de Verdad, de Responsabilidad y de Determinación de los Hechos y Conductas, de conformidad con la Ley 1922 de 2018 por medio de la cual se adoptaron las reglas de procedimiento de esa jurisdicción. ${ }^{[78]}$

Por el contrario, los casos de determinación de responsabilidad inician a través de un sofisticado y complejo proceso, donde interactúan varios órganos de la JEP como la Sala de Reconocimiento de Verdad, de Responsabilidad y de Determinación de los Hechos y Conductas, la Unidad de Investigación y Acusación y el Tribunal para la Paz. La forma en que la JEP adelanta su labor jurisdiccional encaminada al juzgamiento de las conductas parte de la actividad judicial llevada a cabo por la Sala de Reconocimiento, la cual desarrolla un papel muy similar al que tiene una Pre-Trial Chamber en un tribunal penal internacional.

Las funciones de la Sala de Reconocimiento de Verdad, de Responsabilidad y de Determinación de los Hechos y Conductas ${ }^{[79]}$ se centran principalmente en decidir si las conductas atribuidas son competencia del sistema, en recibir y agrupar informes de determinadas entidades estatales y de organizaciones de víctimas y de derechos humanos, recibir declaraciones de aporte de verdad y reconocimiento, para luego, a partir del análisis de todo lo anterior, decidir si emite resolución de conclusiones para que los (macro)casos (priorizados) sean judicializados mediante el principio dialógico que rige los procesos que tienen lugar en la Sección de Primera Instancia con Reconocimiento del Tribunal para la Paz. O, de manera alternativa, decidir si somete a la UIA las conductas no reconocidas para que esta ejerza la acción penal dentro de la JEP y adelante la respectiva acusación dentro de un proceso adversarial ante la Sección de Primera Instancia sin Reconocimiento del Tribunal.

\section{El derecho internacional aplicable para el ejercicio de sus funciones}

Finalmente, se debe precisar que las fuentes normativas para la calificación jurídica de las conductas de conocimiento de esta jurisdicción parten no solo del derecho (penal) nacional, sino que además abarcan las normas del Derecho Internacional en lo concerniente a las reglas y principios contenidos en el DIDH, el DIH y, sobre todo, el DPI ${ }^{[80]}$. Estos recogen conjuntamente instrumentos dirigidos a proteger y materializar efectivamente los derechos humanos hasta llegar al ámbito de la responsabilidad individual ${ }^{[81]}$, lo cual coadyuva a la labor de garantía jurisdiccional tanto de los derechos de los comparecientes, como de las víctimas, al existir un cuerpo normativo más amplio, ajustado a los desarrollos internacionales y que implica la aplicación favorable de disposiciones normativas nacionales e internacionales que hacen parte del bloque de constitucionalidad. 
Sobre la potestad de los jueces de calificar las conductas de su conocimiento acudiendo al Derecho Internacional, el texto constitucional establece:

La JEP al adoptar sus resoluciones o sentencias hará una calificación jurídica propia del Sistema respecto a las conductas objeto del mismo, calificación que se basará en el Código Penal Colombiano y/o en las normas de Derecho Internacional en materia de Derechos Humanos (DIDH), Derecho Internacional Humanitario (DIH) o Derecho Penal Internacional (DPI), siempre con aplicación obligatoria del principio de favorabilidad ${ }^{[82]}$.

En igual sentido está planteado en el art. 23 de la Ley 1957 de 2019, que refiere al derecho aplicable por parte del Tribunal para la Paz, las Salas de Justicia y la Unidad de Investigación y Acusación. Esta disposición estatutaria retoma lo dispuesto en el texto constitucional, agregando en su inc. $2^{\circ}$ que "[l]a calificación resultante podrá ser diferente a la efectuada con anterioridad por las autoridades judiciales, disciplinarias o administrativas para la calificación de esas conductas, por entenderse aplicable como marco jurídico de referencia el Derecho Internacional". Al respecto, la Corte Constitucional, en ejercicio de su control normativo previo sobre esta norma, sostuvo que la constitucionalidad de esta disposición se funda en: "[l]a importancia de que la Justicia Especial para la Paz cuente con instrumentos normativos del orden nacional e internacional para sustentar sus decisiones en el marco constitucional de la justicia transicional en Colombia, en relación con su ámbito competencial” ${ }^{[83]}$.

Aparte del papel que juega el derecho internacional en el derecho sustantivo aplicable en la JEP para la calificación jurídica, las reglas de procedimiento de esta jurisdicción señalan en su cláusula remisoria que, en el ámbito del derecho adjetivo aplicable, en todos los procesos que se adelanten ante la JEP sobre víctimas de violencia basada en género, en especial de violencia sexual, se debe proceder "de conformidad con lo previsto en el bloque de constitucionalidad [y] las Reglas de Procedimiento y Prueba del Estatuto de Roma” [84] . Con ello, la Ley 1922 de 2018 establece la posibilidad de remitirse a disposiciones normativas procedimentales y probatorias que hacen parte del DPI para ser aplicadas en los procesos que se adelanten en la JEP.

Si bien la aplicación directa y autónoma de derecho internacional para la calificación jurídica puede resultar problemática debido a que su uso directo sin adaptación ni articulación jurídica al ordenamiento penal colombiano podría generar afectaciones a principios como el de legalidad, en casos - por ejemplodel empleo retroactivo de la figura de responsabilidad por el mando para fundamentar la responsabilidad penal individual ${ }^{[85]}$, la posibilidad de recurrir al derecho internacional tanto sustantivo como adjetivo, de conformidad con lo permitido por las disposiciones constitucionales y legales citadas, pareciera que adquiere una nueva connotación práctica que va más allá de la usual aplicación judicial del mismo mediante las ya conocidas figuras del bloque de constitucionalidad y del control de convencionalidad.

Esto se puede deducir no solo de la especificidad de las normas citadas, sino también de la postura fijada por la Sección de Apelación mediante sentencia interpretativa, en la que precisa, entre otras cosas, que mediante este tipo de sentencias - con fuerza jurídica vinculante - da uniformidad interpretativa a la aplicación de disposiciones contenidas en instrumentos internacionales sobre derechos humanos, derecho penal y derecho internacional humanitario, que suelen ser normas jurídicas de textura abierta ${ }^{[86]}$.

\section{Conclusiones}

Con base en lo planteado en este artículo de reflexión, es posible sostener que tanto el Tribunal para la Paz como las Salas de Justicia de la JEP son órganos jurisdiccionales que han sido creados atendiendo a una rica y progresiva herencia nacional e internacional en la estructuración de instituciones que buscan judicializar las más graves violaciones de derechos humanos. La JEP constituye el primer escenario judicial negociado y acordado políticamente para superar un conflicto armado de carácter no internacional, que ha sido creado en fecha posterior a la ratificación del Estatuto de Roma. 
Con el diseño de la JEP se ha innovado en términos de ingeniería constitucional debido a su atípica y compleja estructuración institucional, en donde el Tribunal para la Paz, sin ser en estricto sentido jurídico un tribunal híbrido o mixto, se acerca más en términos estructurales, institucionales y funcionales a estos que a los tribunales ordinarios de la justicia nacional.

Debido a las particularidades de la negociación y de la fuerte influencia de los desarrollos dados por el derecho internacional, este ha sido el primer escenario de pacificación que ha tenido Colombia, en el que se han atendido considerablemente estándares internacionales dirigidos no solo a la persecución penal de los crímenes más representativos y, en especial, de sus máximos responsables, sino también a la concesión más amplia de amnistía bajo un estricto modelo de perdones responsabilizantes y condicionados. Dentro de este sistema integral y holístico de justicia transicional, el régimen de condicionalidad pasa a ser el principal prisma jurídico que irradia todos los componentes judiciales y extrajudiciales del SIVJRNR del cual hace parte la JEP. Este régimen es una garantía jurisdiccional para la materialización efectiva de los derechos de las víctimas a la verdad, justicia, reparación y no repetición.

Se debe advertir, además, que la JEP no hace justicia solo para los colombianos, sino que atiende a un mandato y a un deber supranacional de persecución penal de crímenes consensuados por la comunidad internacional, que, por lo tanto, ofenden y agravian a la especie humana más que a los nacionales de un solo país. Los crímenes que persigue, si bien han sido perpetrados en Colombia y han afectado principalmente a los colombianos, estremecen y preocupan a todos los miembros del sistema universal de protección de derechos humanos y despiertan la solidaridad de diferentes naciones. A tal punto de que varios Estados han acompañado y hasta financiado la puesta en funcionamiento de la JEP y varios foros internacionales inclusive el Consejo de Seguridad de Naciones Unidas- han sido epicentro de pronunciamientos que han respaldado tanto el proceso de paz, como la implementación del sistema integral y de esta jurisdicción.

Si estos crímenes no son investigados ni juzgados en esta instancia nacional, pueden llegar a escenarios internacionales y foráneos, en donde se podría reclamar el conocimiento de estos, bien sea por la complementariedad que pueda activar la Corte Penal Internacional o porque un tercer Estado en virtud del principio de jurisdicción universal así lo considere. Pues bien, dentro del sistema de justicia penal internacional contemporáneo, estructurado en tres niveles ${ }^{[87]}$, el Estado territorial y el Estado del procesado tienen conocimiento prioritario ( primer nivel), pero de manera secundaria se asigna competencia complementaria a la CPI (segundo nivel), así como también a terceros Estados con fundamento en el principio de jurisdicción universal (tercer nivel) ${ }^{[88]}$. En este contexto, la JEP representa indudablemente una institución del orden nacional que ha sido creada para que el Estado territorial (en el primer nivel) aborde de manera especializada, preferente y prevalente esta tarea de juzgar los crímenes más representativos acontecidos en el conflicto.

En suma, la JEP busca emular la labor de los tribunales internacionales y mixtos en la tarea de juzgar los crímenes más representativos que han acontecido en el conflicto armado colombiano en el marco de lo que se ha denominado la lucha universal contra la impunidad. Esta jurisdicción reúne a un conjunto de órganos sui generis a la luz del derecho nacional e internacional, los cuales desplazan en el conocimiento de las conductas asociadas con el conflicto a la justicia ordinaria y a sus órganos jurisdiccionales, que, por regla general, habían tenido competencia sobre estos asuntos hasta el $1^{\circ}$ de diciembre de 2016.

\section{Bibliografía}

Aaron Fitchtelberg, Hybrid tribunals: a comparative examination (Springer, 2015).

Acto Legislativo 01 de 2012 [Congreso de Colombia]. Por medio del cual se establecen instrumentos jurídicos de justicia transicional en el marco del artículo 22 de la Constitución Política.

Acto legislativo 01 de 2017 [Congreso de Colombia]. Por medio del cual se crea un título de disposiciones transitorias de la constitución de una paz estable y duradera y se dictan otras disposiciones. 4 de abril de 2017. 
Acuerdo 01 de 2018 de la Sala Plena de la JEP. Por el cual se adopta el reglamento general de la jurisdicción especial para la Paz. 9 de marzo de 2018.

Acuerdo Final de Paz [Gobierno Nacional y FARC-EP]. Acuerdo final para la terminación del conflicto y la construcción de una paz estable y duradera. 12 de noviembre de 2016. https://www.cancilleria.gov.co/sites/def ault/files/Fotos2016/12.11_1.2016nuevoacuerdofinal.pdf

Acuerdo parcial sobre las Víctimas del Conflicto (s. f.). http://www.altocomisionadoparalapaz.gov.co/procesos-y-con versaciones/proceso-de-paz-con-las-farc-ep/Documents/acuerdo-victimas.pdf

Caitlin Carroll, Hybrid Tribunals are the Most Effective Structure for Adjudicating International Crimes Occurring Within a Domestic State, Law School Student Scholarship Paper, n. ${ }^{\circ}$ 90, 1-30 (2013). https://scholarship.shu.e $\mathrm{du} / \mathrm{cgi} / \mathrm{viewcontent}$.cgi?article $=1090 \&$ context $=$ student_scholarship

Christine Bell, On the law of peace: peace agreements and the lex pacificatoria (Oxford University Press, 2008). http s://doi.org/10.1093/acprof:oso/9780199226832.001.0001

Comisión Internacional de Juristas, Colombia: Jurisdicción Especial para la Paz, análisis a un año y medio de su entrada en funcionamiento (International Commission of Jurists, 2019)

Diego Tarapués, El sistema integral de justicia transicional y sus mecanismos para satisfacer el derecho a la justicia de cara al deber estatal de investigar, juzgar y sancionar, en Justicia Transicional, Reforma Constitucional y Paz: Reflexiones sobre la Estrategia Integral de Justicia Transicional en Colombia, 155-179 (D. Tarapués, Ed., Editorial USC, 2017).

Corte Constitucional de Colombia. Sentencia C-080 de 2018 (M. P. Antonio José Lizarazo Ocampo; 15 de agosto de 2018).

Corte Constitucional de Colombia. Sentencia C-674 de 2017 (M. P. Luis Guillermo Guerrero Pérez; 14 de noviembre de 2017).

Corte Constitucional de Colombia. Sentencia SU-139 de 2019 (M. P. Carlos Bernal Pulido; 28 de marzo de 2019).

Declaración de principios (s. f.). http://www.altocomisionadoparalapaz.gov.co/mesadeconversaciones/PDF/Comun icado\%20-Conjunto\%2C\%20La\%20Habana\%2C\%2007\%20de\%20junio\%20de\%202014\%2C\%20Versi_n\% 20Espa_ol.pdf

Decreto 587 de 2017. Por el cual se conforma el Comité de Escogencia para la selección de unos miembros del Sistema Integral de Verdad, Justicia, Reparación y No Repetición (SIVIRNR). 5 de abril de 2017.

Diego Tarapués, La naturaleza institucional del Tribunal Constitucional en América del Sur (JGHG Publicaciones \& Editorial USC, 2008).

Eduardo Pastrana, Comentario al art.1, en Ley de Amnistía: Comentario completo y sistemático (Ley 1820 de 2016), 3-23 (K. Ambos \& G. Cote, Ed., Temis, Cedpal, Capaz \& KAS, 2019).

Fondo Colombia en Paz. http://www.posconflicto.gov.co/consejeria/Paginas/Fondo-Colombia-en-Paz.aspx (5 de abril de 2018).

Gerhard Werle \& Florian Jessberger, Principles of international criminal law (Oxford University Press, 3.. ed., 2014). https://doi.org/10.1093/law/9780198703594.001.0001

Gerhard Werle, Tratado de Derecho Penal Internacional (Tirant lo blanch, $2^{\circ}$ ed., 2011).

Gustavo Cote \& Diego Tarapués, El Marco Jurídico para la Paz y el Análisis Estricto de Sustitución de la Constitución realizado en la Sentencia C-579 de 2013, en Justicia de Transición y Constitución, 197-261 (Kai Ambos ed., Temis, Cedpal \& KAS, 2014).

Gustavo Cote, La responsabilidad por el mando en el Acuerdo de Paz firmado por el Gobierno Colombiano y las FARCEP: un análisis sobre la base del caso Bemba de la Corte Penal Internacional, 15 Nuevo Foro Penal, n. ${ }^{\circ}$ 92, 153-199 (2019). https://doi.org/10.17230/nfp.15.92.4

I Kai Ambos \& Susann Aboueldahab, Juristas extranjeros en la jurisdicción especial para la paz: ¿un nuevo concepto de amicus curiae?, en Contribuciones al Derecho Contemporáneo: Derechos Humanos y Justicia Transicional, 25-46 (Diego Tarapués \& Adolfo Murillo coords., Diké \& Editorial USC, 2018). 
I Kai Ambos, Treatise on International Criminal Law: Foundations and General Part, (Oxford University Press, 2013). https://doi.org/10.1093/law/9780199657926.001.0001

III Kai Ambos, Treatise on International Criminal Law: International Criminal Procedure (Oxford University Press, 2016).

Informe Fuentes de financiación ejecución recursos Jurisdicción especial para la paz (6 de abril de 2018). https://www.jep.gov.co/Sala-de-Prensa/Paginas/Informe-Fuentes-de-financiaci\%C3\%B3n-ejecuci\%C 3\%B3n-recursos-JEP.aspx

Juan Manuel Santos, La batalla por la paz (Planeta, 2019).

Kai Ambos \& Mohammed Othman (eds.), New Approaches in International Criminal Justice (Freiburg im Breisgau, 2003).

Kai Ambos, Florian Huber, Rodrigo A. González-Fuente Rubilar \& John E. Zuluaga Taborda, Procedimiento de la Ley de Justicia y Paz (Ley 975 de 2005) y Derecho Penal Internacional. Estudio sobre la facultad de intervención complementaria de la Corte Penal Internacional a la luz del denominado proceso de "justicia y paz" en Colombia (Deutsche Gesellschaft für Technische Zusammenarbeit (GTZ) GmbH, 2010). http://www.corteidh.or.cr/tab las/26869.pdf

Kai Ambos, Internationales Strafrecht (5ºd., Beck, 2018). https://doi.org/10.17104/9783406746697

Kai Ambos, Protección de Derechos Humanos e internacionalización del derechopenal, Revista Penal, n. ${ }^{\circ}$ 30, 3-12 (2012). https://dialnet.unirioja.es/servlet/articulo?codigo $=3981116$

Ley 1820 de 2016. Por medio de la cual se dictan disposiciones sobre amnistía, indulto y tratamientos penales especiales y otras disposiciones. 30 de diciembre de 2016. D. O. 50102.

Ley 1922 de 2018. Por medio del cual se adoptan unas Reglas de Procedimiento para la Jurisdicción Especial para la Paz. 18 de julio de 2018. D. O. 50658.

Ley 1957 de 2019. Ley Estatutaria de la Administración de Justicia en la Jurisdicción Especial para la Paz. 6 de junio de 2019. D. O. 50976.

Ley 600 de 2000. Código de Procedimiento Penal.

Ley 906 de 2004. Código de Procedimiento Penal.

Luis Orjuela, La competencia jurisdiccional entre la justicia penal militar y la justicia ordinaria (Ibáñez, 2018).

Natalia Silva, Comentario al art.7, en Ley de Amnistía: Comentario completo y sistemático (Ley 1820 de 2016), 80-85 (K. Ambos \& G. Cote, Ed., Temis, Cedpal, Capaz \& KAS, 2019).

Raúl Sánchez (ed.), Marco normativo de la Jurisdicción Especial para la Paz (JEP) (Tirant lo blanc, 2019).

Rodrigo Uprimny, Las enseñanzas del análisis comparado: procesos transicionales, formas de justicia transicional y el caso colombiano, en ¿Justicia transicional sin transición? Verdad, justicia y reparación para Colombia (Rodrigo Uprimny et al. eds., Dejusticia, 2006).

SRVR de la JEP, auto 061 de 2019 (M. P. Diana Fajardo Rivera; 13 de febrero de 2019).

Tribunal para la Paz, auto TP-SA 020 de 2018. Por el que la Sección de Apelación del Tribunal para la Paz resuelve el recurso de apelación interpuesto por el abogado del señor Álvaro Antonio Ashton (3 de octubre de 2018).

Tribunal para la Paz, Auto TP-SA 048 de 2018.

Tribunal para la Paz, Auto TP-SA 068 de 2018.

Tribunal para la Paz, Auto TP-SA 070 de 2018.

Tribunal para la Paz. Sentencia SRT-AE 030 de 2019.

Tribunal para la Paz. Sentencia TP-SA-SENIT 01 de 2019.

UN Multi-Partner Trust Fund for Sustaining Peace in Colombia. http://mptf.undp.org/factsheet/fund/4CO00 


\section{Notas}

[1] Así se desprende del Acuerdo Final, núm. 5.1. Sistema Integral de Verdad, Justicia, Reparación y No Repetición, b. Componentes, y del Acto Legislativo 01 de 2017 en su art. 5.

[2] Esto se reafirma especialmente en los artículos 2 y 29 de la Ley Estatutaria de la JEP. En el primero de ellos se aclara: "El componente de justicia del Sistema Integral de Verdad, Justicia, Reparación y No Repetición (SIVJRNR) se denomina Jurisdicción Especial para la Paz. Los objetivos del componente de justicia del SIVJRNR son satisfacer el derecho de las víctimas a la justicia, ofrecer verdad a la sociedad colombiana, proteger los derechos de las víctimas, contribuir al logro de una paz estable y duradera, y adoptar decisiones que otorguen plena seguridad jurídica a quienes participaron de manera directa o indirecta en el conflicto armado interno, en especial respecto a hechos cometidos en el marco del mismo y durante este que supongan graves infracciones del Derecho Internacional Humanitario y graves violaciones de los Derechos Humanos". En la segunda disposición mencionada se alude al "Deber del estado de investigar, esclarecer, perseguir y sancionar", especificando que: "En materia de justicia, conforme al DIDH, el Estado colombiano tiene el deber de debida diligencia en la investigación, esclarecimiento, persecución y sanción de las graves violaciones del DIDH y las graves infracciones del DIH”. Al respecto, véase también: Diego Tarapués, El sistema integral de justicia transicional y sus mecanismos para satisfacer el derecho a la justicia de cara al deber estatal de investigar, juzgar y sancionar, en Justicia Transicional, Reforma Constitucional y Paz: Reflexiones sobre la Estrategia Integral de Justicia Transicional en Colombia, 175 (D. Tarapués, Ed., Editorial USC, 2017).

[3] Sobre la creación de las Salas de Justicia y Paz dentro de los Tribunales Superiores de Distrito Judicial, véase: Kai Ambos, Florian Huber, Rodrigo A. González-Fuente Rubilar \& John E. Zuluaga Taborda, Procedimiento de la Ley de Justicia y Paz (Ley 975 de 2005) y Derecho Penal Internacional. Estudio sobre la facultad de intervención complementaria de la Corte Penal Internacional a la luz del denominado proceso de "justicia y paz" en Colombia, 39-40 (Deutsche Gesellschaft für Technische Zusammenarbeit (GTZ) GmbH, 2010).

[4] Sobre la Unidad Nacional de Fiscalías para la Justicia y la Paz de la Fiscalía General de la Nación véase: Kai Ambos, op. cit., 38 y 39 .

[5] En detalle véase: Kai Ambos, Florian Huber, Rodrigo A. González-Fuente Rubilar \& John E. Zuluaga Taborda, op. cit.

[6] Al respecto, véase Acto Legislativo 01 de 2012 [Congreso de Colombia]. Por medio del cual se establecen instrumentos jurídicos de justicia transicional en el marco del artículo 22 de la Constitución Política; Diego Tarapués, op. cit., 170 y ss. y Gustavo Cote \& Diego Tarapués, El Marco Jurídico para la Paz y el Análisis Estricto de Sustitución de la Constitución realizado en la Sentencia C-579 de 2013, en Justicia de Transición y Constitución, 197 y ss. (Kai Ambos ed., Temis, Cedpal \& KAS, 2014).

[7] Sobre los tribunales ad hoc de Núremberg, para el Lejano Oriente, para la ex Yugoslavia y para Ruanda, que han sido modelos de justicia impuesta, así como de tribunales ex post facto de naturaleza hibrida y que han sido consensuados entre las diferentes naciones y organismos internacionales, véase I Kai Ambos, Treatise on International Criminal Law: Foundations and General Part, 40 y ss. (Oxford University Press, 2013); Gerhard Werle, Tratado de Derecho Penal Internacional (Tirant lo blanch, $2^{\circ}$ ed., 2011) y Gerhard Werle \& Florian Jessberger, Principles of international criminal law, 1 y ss. (Oxford University Press, 3.a ed., 2014).

[8] Es decir, el diseño contemplado en lo que fue el documento del primer Acuerdo Final suscrito el 26 de septiembre de 2016, el cual fue objeto de refrendación directa por la ciudadanía mediante el plebiscito por la paz el día 2 de octubre de ese año; refrendación donde se sobrepuso el "No" y que generó un espacio de renegociación antecedido por acuerdos alcanzados con los representantes del sector que ganó el plebiscito. Este modelo, que apuntaba a una especie de tribunal mixto con la inclusión de jueces extranjeros, fue el acordado inicialmente por las partes que adoptaron el acuerdo parcial sobre justicia transicional y víctimas alcanzado en la mesa de negociaciones de La Habana en septiembre de 2015 y que hizo parte del Acuerdo de Víctimas fechado el 15 de diciembre de 2015.

[9] $\mathrm{Al}$ respecto véase, por ejemplo: Aaron Fitchtelberg, Hybrid tribunals: a comparative examination, 75 y ss. (Springer, 2015); Caitlin Carroll, Hybrid Tribunals are the Most Effective Structure for Adjudicating International Crimes Occurring Within a Domestic State, Law School Student Scholarship Paper, n. ${ }^{\circ}$ 90, 1-30 (2013); Kai Ambos \& Mohammed Othman (eds.), New Approaches in International Criminal Justice (Freiburg im Breisgau, 2003); Kai Ambos, op. cit., 40 y ss.; III Kai Ambos, Treatise on International Criminal Law: International Criminal Procedure, 30 y ss. (Oxford University Press, 2016).

[10] Werle enfatiza en que el más "internacional” de estos tribunales es el Tribunal Especial (Special Court) para Sierra Leona, creado en virtud de un acuerdo celebrado entre las Naciones Unidas y Sierra Leona en 2002. Señala que el propio tribunal en decisión de mayo 31 de 2004 (Taylor, AC, parágrafo 42), se autoreconoció como tribunal internacional, a lo que se suma que "es una entidad con personalidad jurídica propia, distinta de -y con primacía sobre- los tribunales nacionales de Sierra Leona”. Cfr. Gerhard Werle, op. cit., 191 y ss. y Gerhard Werle \& Florian Jessberger, op. cit., 95 y ss.

[11] Gerhard Werle, op. cit., 191 y 197. 
[12] Caitlin Carroll, op. cit., 25 y 26.

[13] Cfr. art. transitorio 22 del art. 1 del Acto legislativo 01 de 2017 [Congreso de Colombia]. Por medio del cual se crea un título de disposiciones transitorias de la constitución de una paz estable y duradera y se dictan otras disposiciones. 4 de abril de 2017; y Corte Constitucional de Colombia. Sentencia C-080 de 2018, núm. 4.2. Análisis constitucional del articulado.

[14] Esto de conformidad con el inciso $1^{\circ}$ del art. transitorio 12 del art. 1 el AL 01 de 2017. Sin embargo, hay que resaltar que, en una aparente contradicción a este precepto fundamental, la Ley 1922 de 2018 en su art. $1^{\circ}$ ha establecido que se debe respetar y garantizar la “(...) libertad de escoger profesional del derecho con acreditación, que se encuentra legalmente autorizado por la legislación colombiana para apoderar a personas que deban acudir ante autoridad judicial o administrativa".

[15] Los recursos que se han empleado para la puesta en marcha de la JEP provenían del Fondo Multidonante para el Posconflicto (de enero a octubre de 2017) y del Fondo Colombia en Paz (de noviembre de 2017 a marzo de 2018). Sobre los detalles de estos fondos y la elevada contribución de la cooperación internacional para poner en funcionamiento a la JEP, véase: Informe Fuentes de financiación ejecución recursos Jurisdicción especial para la paz. https://www.jep.gov.co /Sala-de-Prensa/Paginas/Informe-Fuentes-de-financiaci\%C3\%B3n-ejecuci\%C3\%B3n-recursos-JEP.aspx (6 de abril de 2018); UN Multi-Partner Trust Fund for Sustaining Peace in Colombia. https://www.mptf.undp.org/factsheet/fund/ 4CO00; Fondo Colombia en Paz. https://www.posconflicto.gov.co/consejeria/Paginas/Fondo-Colombia-en-Paz.aspx ( 5 de abril de 2018). En general, sobre el amplio respaldo de la comunidad internacional véase: Comisión Internacional de Juristas, Colombia: Jurisdicción Especial para la Paz, análisis a un año y medio de su entrada en funcionamiento (International Commission of Jurists, 2019)

[16] Este tipo de rasgos distintivos ha servido para evaluar la naturaleza institucional de otros órganos jurisdiccionales como tribunales constitucionales, véase, por ejemplo: La naturaleza institucional del Tribunal Constitucional en América del Sur142 y ss. (JGHG Publicaciones\& Editorial USC, 2008).

[17] Al respecto, véase lo referente al Acuerdo de Paz en Colombia como un "Acuerdo Especial” según el DIH en Eduardo Pastrana, Comentario al art.1, en Ley de Amnistía: Comentario completo y sistemático (Ley 1820 de 2016), 3-23 (K. Ambos \& G. Cote, Ed., Temis, Cedpal, Capaz \& KAS, 2019).

[18] Esto a la luz del concepto desarrollado por Bell sobre la "ley de los pacificadores" que comprende las innovaciones jurídicas derivadas de procesos de negociación y acuerdos de paz donde se forjan adaptaciones jurídicas internacionales y constitucionales para la superación de conflictos armados. Cfr. Christine Bell, On the law of peace: peace agreements and the lex pacificatoria (Oxford University Press, 2008).

[19] Rodrigo Uprimny, Las enseñanzas del análisis comparado: procesos transicionales, formas de justicia transicional y el caso colombiano, en ¿ Justicia transicional sin transición? Verdad, justicia y reparación para Colombia, 21-32 (Rodrigo Uprimny et al. eds., Dejusticia, 2006).

[20] Rodrigo Uprimny, op. cit., 32-38.

[21] Rodrigo Uprimny, op. cit., 24 y ss.

[22] Declaración de principios (s. f.).

[23] Inc. $8^{\circ}$ del art. transitorio $5^{\circ}$ del art. 1 del AL 01 de 2017, arts. 14, 33 y 50 de la Ley 1820 de 2016, arts. 67 y 69 de la Ley 1922 de 2018 y art. 20 de la Ley 1957 de 2019. Véase también SRVR de la JEP, auto 061 de 2019, párr. 56 y ss.

[24] Acuerdo parcial sobre las Víctimas del Conflicto (s. f.).

[25] Raúl Sánchez (ed.), Marco normativo de la Jurisdicción Especial para la Paz (JEP), 15-16 (Tirant lo blanc, 2019).

[26] Al respecto, véase: Juan Manuel Santos, La batalla por la paz, 475-478 (Planeta, 2019)

[27] Cfr. art. transitorio 19 del art. 1 del AL 01 de 2017 y Tribunal para la Paz. Sentencia SRT-AE 030 de 2019 , párr. 152 y ss.

[28] Así lo ha dicho la Corte Constitucional al revisar la constitucionalidad de los artículos transitorios 16 y 17 del AL 01 de 2017: "No ocurre lo propio, sin embargo, en relación con quienes no tienen la calidad de combatientes y no se someten voluntariamente a la Jurisdicción Especial para la Paz, ni en relación con los destinatarios de los fueros constitucionales. En relación con estos sujetos, el acceso forzoso a la JEP sí suprime la garantía del juez natural, en la medida en que, por un lado, se dispuso un traslado de atribuciones de la jurisdicción ordinaria a la JEP, en asuntos que comprometen directamente la libertad individual por referirse a la investigación y sanción de los delitos, y en la medida en que, por consiguiente, bajo el nuevo modelo competencial se produjo una alteración de ex post y ad hoc de las reglas de competencia, del órgano judicial, y del régimen jurídico al que se encuentran sometidos dichos sujetos, en relación con las infracciones cometidas en el marco del conflicto armado antes del $1^{\circ}$ de diciembre de 2016", Corte Constitucional de Colombia. Sentencia C-674 de 2017, punto 5.5.2.4.

[29] En efecto, la Corte ha señalado que la JEP es el juez de los ex combatientes del conflicto armado y ha precisado que la introducción de este nuevo juez no viola la garantía del juez natural ni el debido proceso en general. Al respecto afirma la Corte: "El debido proceso es entonces, aun en la justicia transicional «piedra angular» irremplazable, y si bien es cierto puede flexibilizarse en aspectos tales como los términos judiciales o la creación de órganos de judicialización entre otros, no podría anular los aspectos que conforman su núcleo esencial, en ese sentido, aun cuando se encuentre que la 
creación de una nueva institucionalidad no desconoce la Constitución ni el parámetro del Juez natural, lo cierto es que, ese nuevo juez -ahora el natural de los ex combatientes- deberá respetar al interior de todas sus actuaciones, el debido proceso y la legalidad especial y transicional que regula sus actos", sentencia C-112 de 2019, párr. 48. Asimismo, al revisar la constitucionalidad del AL 01 de 2017 sostuvo: "la creación de una nueva jurisdicción para el juzgamiento de los delitos cometidos en el marco del conflicto armado no anula la garantía del juez natural”, Corte Constitucional de Colombia. Sentencia C-674 de 2017, punto 5.5.2.1.

[30] Al respecto, véase, por ejemplo: Tribunal para la Paz, auto TP-SA 020 de 2018, párr. 16 y ss., 78 y ss.

[31] Inc. $1^{\circ}$ del art. trans. 5 del art. 1 del AL 01 de 2017. La misma disposición normativa se reproduce en el art. 8 de la Ley Estatutaria de la JEP.

[32] Inciso $1^{\circ}$ del art. transitorio 5 del art. 1 del AL 01 de 2017 y arts. 63 y 64 de la Ley 1957 de 2019.

[33] Inciso $1^{\circ}$ del art. transitorio 5 del art. 1 del AL 01 de 2017 y art. 65 de la Ley 1957 de 2019.

[34] Inciso $1^{\circ}$ del art. transitorio 5 y art. transitorio 23 del art. 1 del AL 01 de 2017 y art. 62 de la Ley 1957 de 2019.

[35] Véase: Tribunal para la Paz, autos TP-SA 020, 048, 068 y 070 de 2018.

[36] Inciso $1^{\circ}$ del art. transitorio 6 del art. 1 del AL 01 de 2017.

[37] Cfr. Art. 36 de la Ley 1957 de 2019. También en el art. 7 de la Ley 1820 de 2016 se abordan los alcances del principio de prevalencia, aunque como principio aplicable a la hora de fijar el régimen de beneficios de menor y mayor entidad que consagra esta ley, los cuales "prevalecerán sobre las actuaciones de cualquier jurisdicción o procedimiento, en especial sobre actuaciones penales, disciplinarias, administrativas, fiscales o de cualquier otro tipo, por conductas ocurridas en el marco del conflicto interno, por causa, con ocasión o en relación directa o indirecta a este”. Al respecto, véase Natalia Silva, Comentario al art.7, en Ley de Amnistía: Comentario completo y sistemático (Ley 1820 de 2016), 80-85 (K. Ambos \& G. Cote, Ed., Temis, Cedpal, Capaz \& KAS, 2019).

[38] Corte Constitucional de Colombia. Sentencia C-674 de 2017, punto 4.5.2.4. (xiii).

[39] Inciso $2^{\circ}$ del art. transitorio 6 del art. 1 del AL 01 de 2017

[40] Acuerdo Final de Paz [Gobierno Nacional y FARC-EP]. Acuerdo final para la terminación del conflicto y la construcción de una paz estable y duradera. 12 de noviembre de 2016, puntos 5.1.2, numerales 9, 15 y 33, pp. 145, 146 y 149 ; Corte Constitucional de Colombia. Sentencia C-674 de 2017, punto 4.4.9.

[41] Kai Ambos clasifica el modelo inicial de la JEP dentro de la misma categoría del Alto Tribunal Penal Iraquí (Iraqi Higher Criminal Court) y del Tribunal de Crímenes Internacionales de Bangladesh (International Crimes Tribunal in Bangladesh), ya que esos tres casos no se basan en un acuerdo bilateral con la ONU o con alguna organización regional como sí sucede en los casos del Tribunal Especial para el Líbano (Special Tribunal for Lebanon), del Tribunal para el Genocidio Camboyano (Extraordinary Chambers in the Court of Cambodia) o del Tribunal Especial para Sierra Leona (Special Court for Sierra Leone), ni tampoco forman parte de una administración de transición de Naciones Unidas o de una organización regional como en los casos de Timor Oriental con la ONU y de Kosovo con la Unión Europea. Cfr. Kai Ambos, op. cit., 30-44 (2016).

[42] Acuerdo Final (versión inicial suscrita el 26 de septiembre de 2016), núm. 5.1.2. Justicia, párr. 65.

[43] Acuerdo Final (versión inicial suscrita el 26 de septiembre de 2016), núm. 5.1.2. Justicia, párr. 66.

[44] I Kai Ambos \& Susann Aboueldahab, Juristas extranjeros en la jurisdicción especial para la paz: ¿un nuevo concepto de amicus curiae?, en Contribuciones al Derecho Contemporáneo: Derechos Humanos y Justicia Transicional, 27 (Diego Tarapués \& Adolfo Murillo coords., Diké \& Editorial USC, 2018). Estos autores también señalan que además del rol de los "los jueces extranjeros para la salvaguarda del cumplimiento del derecho penal internacional, ellos también podrían servir como escudo protector contra la influencia e interferencia de la política doméstica”.

[45] Al respecto, el art. transitorio 7 del Acto Legislativo 01 de 2017 establece: “(...) El Tribunal para la Paz estará conformado por un mínimo de 20 magistrados colombianos titulares. Además, se contará con 4 juristas expertos extranjeros que intervendrán. Excepcionalmente, a solicitud de las personas sometidas a su jurisdicción o de oficio, la Sección que vaya a conocer el caso pedirá la intervención, como amicus curiae, de hasta 2 juristas extranjeros de reconocido prestigio. Estos últimos actuarán con la única finalidad de aportar un concepto o amicus curiae sobre la materia del caso bajo estudio, con el fin de obtener elementos de juicio o informaciones relevantes al caso". La misma figura del amicus se contempla también en la conformación de las Salas: “(...) se contará con 6 juristas expertos extranjeros. Excepcionalmente, a solicitud de las personas sometidas a su jurisdicción o de oficio, la Sala que vaya a conocer el caso pedirá la intervención, como amicus curiae, de hasta 2 juristas extranjeros de reconocido prestigio, con el fin de emitir un concepto o amicus curiae sobre la materia del caso bajo estudio, con el fin de obtener elementos de juicio o informaciones relevantes al caso". Sobre el cambio de magistrados extranjeros a amicus extranjeros, véase en detalle: Kai Ambos \& Susann Aboueldahab, op. cit., 26 y ss.

[46] Kai Ambos \& Susann Aboueldahab, op. cit., 28 y 29.

[47] Kai Ambos \& Susann Aboueldahab, op. cit., 32.

[48] En la Sentencia C-674 de 2017, párr. 5.4.11, la Corte sostuvo: “(...) la intervención de estos expertos extranjeros implica introducir un elemento extraño en la función jurisdiccional, que altera de manera sustantiva las dinámicas de deliberación y deliberación de un cuerpo jurisdiccional como la JEP”. 
[49] Además del artículo transitorio 7 del artículo 1 del AL 01 de 2017, la figura del amicus curiae está regulado legalmente en los arts. 98, 99, 101 y 108 de la Ley 1957 de 2019 e internamente en los arts. 43, 48 y 118 del Reglamento Interno de la JEP, Acuerdo 01 de 2018.

[50] Los delegados designados fueron: José Francisco Acuña (Colombia), Diego García Sayán (Perú), Claudia Vaca (Colombia), Álvaro Gil Robles (España) y Juan Méndez (Argentina), respectivamente.

[51] Decreto 587 de 2017. Por el cual se conforma el Comité de Escogencia para la selección de unos miembros del Sistema Integral de Verdad, Justicia, Reparación y No Repetición (SIVIRNR). 5 de abril de 2017, art. 6.

[52] Cfr. art. transitorio 5 del art. 1 del AL 01 de 2017.

[53] Tribunal para la Paz. Sentencia TP-SA-SENIT 01 de 2019, párr. 14.

[54] Corte Constitucional, sentencia C-674 de 2017, punto 5.4.9.

[55] Art. 34 de la Ley 1957 de 2019.

[56] De conformidad con el inciso $2^{\circ}$ del art. transitorio 7 del art. 1 del AL 01 de 2017, el art. 90 de la Ley 1957 de 2019 y el art. 47 del Reglamento Interno de la JEP (Acuerdo 01 de 2018). Igualmente, así lo ha ratificado la jurisprudencia constitucional al señalar: "El Tribunal para la Paz es el órgano rector de la jurisdicción y máxima instancia de la JEP”, Corte Constitucional de Colombia. Sentencia C-674 de 2017.

[57] Corte Constitucional de Colombia, sentencia C-080 de 2018, 4.1.4. Estructura orgánica y características de la Jurisdicción Especial para la Paz.

[58] El Tribunal para la Paz se creó por mandato de los incisos $1^{\circ}$ y $2^{\circ}$ del art. transitorio 7 del art. 1 del AL 01 de 2017. Véase, igualmente, art. 91 de la Ley 1957 de 2019.

[59] Arts. 92 y 93 de la Ley 1957 de 2019.

[60] Art. 97 de la Ley 1957 de 2019.

[61] Arts. 25 y 96 de la Ley 1957 de 2019.

[62] Parágrafo del art. 91 de la Ley 1957 de 2019.

[63] Art. 79 de la Ley 1957 de 2019.

[64] Art. 81 de la Ley 1957 de 2019.

[65] Art. 84 de la Ley 1957 de 2019.

[66] Las Salas de Justicia fueron creadas por mandato de los incisos $1^{\circ}$ y $3^{\circ}$ del art. transitorio 7 del art. 1 del AL 01 de 2017.

[67] La UIA reúne a un equipo de fiscales e investigadores a cargo de un director, quien es autónomo en la conformación de su equipo y en el desarrollo de sus funciones. La UIA de la JEP se creó por mandato de los incisos $1^{\circ}$ y $5^{\circ}$ del art. transitorio 7 del art. 1 del AL 01 de 2017.

[68] De conformidad con el art. 72 de la Ley 1957 de 2019 y el art. 6 del Reglamento Interno de la JEP, Acuerdo 01 de 2018.

[69] La SE agrupa a un conjunto de funcionarios administrativos que responden a la Secretaria Ejecutiva, quien es autónoma en la conformación de su equipo y en el desarrollo de sus funciones. La SE de la JEP se creó por mandato de los incisos $1^{\circ}$ y $9^{\circ}$ del art. transitorio 7 del art. 1 del AL 01 de 2017.

[70] La Presidencia de la JEP se creó por mandato del inciso $1^{\circ}$ del art. transitorio 7 del art. 1 del AL 01 de 2017. Asimismo, véase el art. 6 del Reglamento Interno de la JEP, Acuerdo 01 de 2018.

[71] Si bien el Órgano de Gobierno de la JEP se crea formalmente por el art. 110 de la Ley 1957 de 2019 y por los arts. 12-17, del Reglamento Interno de la JEP, Acuerdo 01 de 2018, el parágrafo $2^{\circ}$ del art. transitorio 5 del art. 1 del AL 01 de 2017 fija las bases constitucionales respecto al gobierno y administración autónoma de esta jurisdicción.

[72] Art. 155 de la Ley 1957 de 2019 y arts. 124-126 del Reglamento Interno de la JEP, Acuerdo 01 de 2018.

[73] Respectivamente regulados en los arts. 70-74, arts. 75-81 y arts. 100-105 del Reglamento Interno de la JEP, Acuerdo 01 de 2018.

[74] Al respecto, véase Luis Orjuela, La competencia jurisdiccional entre la justicia penal militar y la justicia ordinaria (Ibáñez, 2018).

[75] Corte Constitucional de Colombia. Sentencia C-674 de 2017, punto 5.5.2.8.

[76] Al respecto, enfatiza la Corte: "En otras palabras, aunque en principio la creación de una instancia ad hoc y ex post según las directrices de un acuerdo de paz suscrito entre el gobierno nacional y uno de los combatientes en el conflicto armado podría ser admisible en el presente escenario de transición de cara a la garantía del juez natural, lo es únicamente en relación con los combatientes, pero no para someter de manera forzosa a los demás actores, y en particular, a los no combatientes, como los terceros civiles, los agentes del Estado que no integran la fuerza pública, y los propios aforados constitucionales", Corte Constitucional de Colombia. Sentencia C-674 de 2017, punto 5.5.2.8.

[77] Cfr. Códigos de Procedimiento Penal, arts. 26 y ss. De la Ley 600 de 2000 y arts. 66 y ss. de la Ley 906 de 2004.

[78] Corte Constitucional de Colombia. Sentencia SU-139 de 2019, párr. 29.

[79] Véase art. transitorio 15 del art. 1 del AL 01 de 2017, arts. 27-27d de la Ley 1922 de 2018 y arts. 78-80 de la Ley 1957.

[80] Esto fue pactado en el núm. 19 de lo acordado en el punto 5.1.2. Justicia, donde se establece: "Para efectos del SIVJRNR, los marcos jurídicos de referencia incluyen principalmente el Derecho Internacional en materia de Derechos Humanos (DIDH) y el Derecho Internacional Humanitario (DIH). Las secciones del Tribunal para la Paz, las Salas y la Unidad 
de Investigación y Acusación, al adoptar sus resoluciones o sentencias harán una calificación jurídica propia del Sistema respecto a las conductas objeto del mismo, calificación que se basará en el Código Penal colombiano y/o en las normas de Derecho Internacional en materia de Derechos Humanos (DIDH), Derecho Internacional Humanitario (DIH) o Derecho Penal Internacional (DPI), siempre con aplicación obligatoria del principio de favorabilidad". Sobre el particular véase: Acuerdo Final numerales 65, 66 y 68 del punto 5.1.2. junto con el "Acuerdo de desarrollo del numeral 23 del 'Acuerdo de creación de una jurisdicción especial para la paz' del 15 de diciembre de 2015”, propiamente en el punto 5.3 concerniente al acuerdo complementario sobre el "Sistema Integral de Verdad, Justicia, Reparación y No Repetición".

[81] Véase Kai Ambos, Protección de Derechos Humanos e internacionalización del derecho penal, Revista Penal, n. 30 , 3-12 (2012).

[82] Inc. $7^{\circ}$ del art. trans. 5 del art. 1 del AL 01 de 2017.

[83] Corte Constitucional de Colombia. Sentencia C-080 de 2018, núm. 4.2. Análisis constitucional del articulado.

[84] Parágrafo del art. 72 de la Ley 1922 de 2018.

[85] Al respecto, véase el análisis crítico que sostiene Gustavo Cote sobre “por qué resultaría problemático aceptar que éstas son normas penales sustanciales aptas para fundamentar autónomamente la responsabilidad penal individual, sobre todo a luz de los principios de legalidad y culpabilidad". Gustavo Cote, La responsabilidad por el mando en el Acuerdo de Paz firmado por el Gobierno Colombiano y las FARC-EP: un análisis sobre la base del caso Bemba de la Corte Penal Internacional, 15 Nuevo Foro Penal, n. ${ }^{\circ}$ 92, 159 ss. y 177 (2019).

[86] En su primera sentencia interpretativa, la Sección de Apelación señala lo siguiente: "Los instrumentos internacionales sobre derechos humanos, derecho penal y derecho internacional humanitario son de textura abierta en un sinnúmero de materias. Para propiciar consensos, dejar margen a la regulación estatal y no lesionar desproporcionadamente la soberanía, la comunidad internacional acuerda marcos generales. En consecuencia, la justicia transicional contempla cláusulas normativas y diseños institucionales amplios, cuya concreción le corresponde a la JEP, en general, y a la SA, como instancia de cierre hermenéutico. Por otra parte, aunque los derechos humanos se postulan como ideales 'indivisibles' -según la Proclamación de Teherán-e 'interdependientes' - como lo proclama la Declaración de Viena-, la realidad evidencia que en ocasiones están en conflicto. Para alcanzar la aspiración de unidad, indivisibilidad e interdependencia se requiere un esfuerzo interpretativo, que dentro de la JEP deben realizar todos sus órganos. Sin embargo, para darles uniformidad a sus resultados puede acudirse a las Senit, con el fin de asegurar en el universo de la JEP un patrimonio común de conceptos y marcos operacionales enderezados a hacer efectivos los designios del derecho transicional". Tribunal para la Paz, sentencia TP-SA-SENIT 01 de 2019, párr. 22.

[87] Véase Kai Ambos, Internationales Strafrecht, Part II, sección 5, 97 y ss. (5ed., Beck, 2018).

[88] En términos de Werle se trata de un "paralelismo entre mecanismos de aplicación directos e indirectos [que] puede llevar a que tribunales nacionales e internacionales reclamen, al mismo tiempo, el ejercicio de su competencia para la persecución penal", Gerhard Werle, op. cit., 161.

* Artículo de reflexión. Este artículo es producto del proyecto de investigación del CEDPAL (Alemania) denominado: "Ley de Procedimiento de la Jurisdicción Especial para la Paz: aciertos, debilidades y desafíos del derecho penal en contextos de justicia transicional".

\section{Licencia Creative Commons CC BY 4.0}

Cómo citar este artículo: Diego Fernando Tarapués Sandino, El Tribunal para la Paz y las Salas de Justicia de la JEP como órganos jurisdiccionales sui generis, 69 Vniversitas (2020). https://doi.org/10.11144/Javeria na.vj69.tpsj 